\title{
Migrações Contemporâneas: uma análise da produção científica sobre a família no contexto transnacional
}

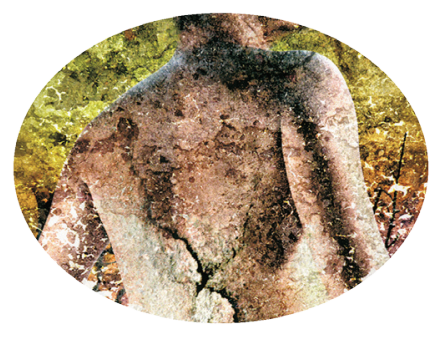

\author{
Arieche Kitiane Silva Lima* \\ Kristiane Alves Araújo** \\ Francilene dos Santos Rodrigues***
}

\section{Resumo}

Este artigo tem como objetivo a síntese de algumas das produções acadêmicas que abordam a temática do deslocamento internacional de populações de países pertencentes à Pan-Amazônia, em especial as implicações desse fenômeno nas relações familiares. Nesse contexto, buscou-se identificar, nos diversos textos, as vivências transnacionais e demais estratégias que permeiam os vínculos familiares durante o processo migratório. Metodologicamente, realizou-se uma pesquisa bibliográfica em que foram analisados seis artigos científicos, publicados no período de 2007 a 2011, que contemplam aspectos diversos dos seguintes temas: família transnacional, migração, conjugalidade e parentalidade. Com a análise foi possível inferir que o deslocamento transnacional, por um lado, acentua algumas experiências familiares e pode aprofundar problemáticas já vivenciadas e, por outro, pode auxiliar na manutenção e reforço dos laços afetivos.

\footnotetext{
* Mestranda do Programa de Pós-Graduação Sociedade e Fronteiras - PPGSOF/UFRR. E-mail: arieche_ lima@hotmail.com

** Mestranda do Programa de Pós-Graduação em Ciências da Saúde - Procisa/UFRR. E-mail: kristianefisioterapia@hotmail.com

*** Professora do Programa de Pós-Graduação Sociedade e Fronteiras - PPGSOF/UFRR.E-mail: francerodrigues@yahoo.com.br
} 
Palavras-chave: Famílias transnacionais; migração; Pan-Amazônia

\begin{abstract}
This article aims at the synthesis of some of the academic productions to the thematic shift international populations of countries within the Pan-Amazonia, especially the implications of this phenomenon in family relationships. In this context, we sought to identify the various texts, experiences and other transnational strategies that permeate family ties during the migration process. Methodologically, we carried out a literature review which examined six scientific papers, published in the period 2007-2011, which cover various aspects of the following topics: family transnational migration, marital and parenting. With the analysis was possible to infer that the transnational movement, on the one hand, accentuates some familiar experiences and may have experienced further problems, and secondly, can assist in maintaining and strengthening the emotional bonds.
\end{abstract}

Keywords: Families transnational migration; Pan-Amazon

\title{
Introdução
}

Este artigo tem como objetivo uma síntese e algumas das principais produções acadêmicas que abordam a temática deslocamento internacional de populações de países pertencentes à Pan-Amazônia e as implicações desse fenômeno nas relações familiares e na (re)constituição de famílias transnacionais. Nesse contexto, serão analisados, nos diversos textos, as vivências transnacionais e demais estratégias que permeiam os vínculos familiares durante o processo migratório.

Metodologicamente, realizou-se uma pesquisa bibliográfica, na qual se selecionou seis artigos científicos de revistas e anais de congressos, em espanhol, que investigam os deslocamentos internacionais de populações de países pertencentes à Pan-Amazônia, em especial os que abordam os temas de família transnacional, migração, conjugalidade e parentalidade. A busca pelos textos foi realizada de forma manual e na base de dados Redalyc (Rede de Revistas Científicas da América Latina, Caribe, Espanha e Portugal), priorizando as publicações do período de 2007 a 2011 e com as seguintes palavras-chave: 
família transnacional, migração e conjugalidade e migração e parentalidade.

Os artigos analisados têm os seguintes títulos: "Familias desde el vivir transnacional: cambios y permanencias en la cotidianidad de las formas familiares en Colombia" (HAYDAR, VÉLEZ e LÓPEZ, 2011); "Familia transnacional y remesas: padres y madres migrantes" (MARTÍNEZ, 2009); "Varones aventureros vs. Madres que abandonan: reconstrucción de las relaciones familiares a partir de la migración ecuatoriana" (PEDONE, 2008); "Prácticas de continuidad de los vínculos parentales en las familias transnacionales colombianas en España - Comunidad Valenciana, España - Eje Cafetero, Colombia” (RINCÓN e PINEDA, 2010); "Afectos y emociones entre padres, madres e hijos en el vivir transnacional" (VILLAMIZAR e MORENO, 2011); "Los vínculos afectivos y de cuidado em las familias transnacionales migrantes ecuatorianos y peruanos en España” (PARELLA, 2007).

Após a realização das leituras, as informações foram sistematizadas e os dados selecionados a partir dos objetivos propostos. Vale salientar que um dos critérios de definição das categorias-chave foi a presença reiterada delas em todos os artigos selecionados, mesmo que em graus de profundidade diferentes. Isso propiciou uma análise comparativa das pesquisas sobre famílias no contexto transnacional. Sendo assim, os dados foram configurados nas seguintes categorias-chave: família transnacional; parentalidade; conjugalidade; cuidadores. Como forma de desenvolvimento do trabalho supracitado, optou-se por realizar primeiro a análise das categorias-chave e segundo a identificação das perspectivas e abordagens teóricas as quais foram consideradas em blocos.

\section{Famílias transnacionais}

A adoção do transnacionalismo como agenda de pesquisa, segundo Sasaki e Assis (2000) e Pedone (2008), significa a escolha por analisar com maior complexidade o estudo do processo de deslocamento baseado nas redes migratórias e a forma como os migrantes constroem e reconstroem suas vidas, simultaneamente em mais de uma localidade.

Valderrama (2007) informa que a discussão sobre o caráter transnacional da migração contemporânea se fortaleceu nos anos 90 , buscando uma visão crítica sobre as teorias tradicionais que pressupunham que os migrantes rompiam relações com as sociedades de origem. 
Autores como Pedone (2008), Martínez (2009) e Parella (2007) indicam que houve necessidade de análises mais abrangentes acerca dos deslocamentos contemporâneos, perpassando a vigorosa ligação do migrante com o país de destino e de origem, considerando as múltiplas relações que são mantidas e o pluralismo cultural. Parella (2007) destaca que o estudo das redes familiares, associadas ao processo migratório, tenta verificar o impacto afetivo e social, além de investigar a existência de práticas transnacionais envolvendo a manutenção de vínculos e enfocando, principalmente, as relações entre gêneros e gerações. Rincón e Pineda (2010: 94) comentam que:

Las familias transnacionales surgen como una respuesta a un mundo globalizado, donde los roles y dinámicas familiares se reorganizan para responder tanto con La proveeduría económica como con la gestión de los cuidados y afectos dentro de la unidad doméstica.

No que diz respeito à articulação transnacional do lar, há um consenso entre os autores dos artigos analisados, de que família transnacional pressupõe a separação física sem a quebra de laços emocionais. Para esses autores, tratase da redefinição de papéis e da construção de redes entre membros da família que estão dispersos entre diferentes Estados nações, por períodos longos ou transitórios, mas com a manutenção do sentimento de pertencimento e coesão familiar (HAYDAR, VELEZ e LÓPEZ, 2011; PARELLA, 2007; MARTÍNEZ, 2009; RINCÓN e PINEDA, 2010; PEDONE, 2008; VILLAMIZAR e MORENO, 2011).

Haydar, Velez e López (2011) e Parella (2007) relatam que a manutenção e reestabelecimento desses laços sustentam-se por meio de redes sociais compostas, principalmente, pela família extensa que faz constantes trocas econômicas, sociais, culturais e afetivas. Rincón e Pineda (2010) relatam que as representações acerca do processo migratório e dos estilos de vínculos afetivos construídas durante todo o processo de convivência familiar, além do cumprimento das promessas feitas antes e após o deslocamento, também são relevantes para a manutenção da conexão familiar.

Martínez (2009) e Pedone (2008) contribuem com a discussão afirmando que o deslocamento dos componentes de uma família para diferentes espaços não determina diretamente o estabelecimento de conflitos e rupturas familiares. 
As referidas autoras fazem uma diferenciação entre dois conceitos associados à família inserida no processo migratório: a fragmentação e a desintegração familiar. A segunda está relacionada à quebra das relações e a primeira à dispersão dos membros do grupo em diferentes localidades sem a perda do vínculo que os une.

Haydar, Velez e López (2011) e Parella (2007) também mencionam que as famílias em situação de transnacionalidade são comunidades imaginadas, pois seus integrantes, estando fisicamente distanciados, conseguem construir a percepção afetiva de proximidade, além de que compartilham elementos do cotidiano e um projeto de reunificação no país de origem ou na comunidade hospedeira.

A respeito das comunidades transnacionais imaginadas, Ribeiro (2000) informa que se caracterizam pela desterritorialização, ambiguidade e simultaneidade, ao mesmo tempo em que há uma transversalidade que vai desde o local até o global. O espaço passa a ser algo difícil de mensurar e as redes sociais e virtuais constituem-se como dimensões centrais para o desenvolvimento da integração transnacional.

Nesse sentido, Sasaki e Assis (2000) e Valderrama (2007) destacam como recorrentes a manutenção dos papéis sociais apesar do distanciamento físico, a participação por meio do voto e da inserção em políticas públicas na comunidade hospedeira e de origem, assim como a dinâmica que ocorre a partir da entrada do migrante no mercado de trabalho e das remessas financeiras.

Haydar, Velez e López (2011), Parella (2007) e Villamizar e Moreno (2011) dizem que, com a experiência migratória, a família se reconfigura pelas estratégias que asseguram a manutenção das suas bases durante o viver transnacional. Essas estratégias de conservação da relação familiar relacionamse principalmente às remessas financeiras, ao sistema de transporte e à evolução tecnológica que permitem a comunicação frequente.

Todos esses elementos geram a percepção de proximidade, mediante negociações e reorganizações constantes entre os familiares, transcendendo o plano físico e os pressupostos tradicionais, reafirmando os laços afetivos, construindo planos comuns, estratégias de cuidado e projeto de reunificação, permanecendo assim entrelaçados (RINCÓN e PINEDA, 2010; VILLAMIZAR e MORENO, 2011). 


\section{Parentalidade transnacional}

A parentalidade pode ocorrer por fatores biológicos e/ou psicossociais, onde há a incorporação de papéis e reorganização da identidade por conta de um novo elemento (o filho), que é incorporado à existência de um subsistema familiar. A parentalidade implica na satisfação das necessidades biopsicossociais dos filhos, buscando-se sempre a promoção do seu bem-estar (FERÉSCARNEIRO, 2010).

Fonseca, Feitosa e Lima (2004) informam que a principal função da família e, mais especificamente, do subsistema parental, é a socialização primária dos filhos. O afeto é um importante elemento nessa dinâmica, pois fornece segurança emocional e inibe comportamentos agressivos. Wagner (2011) reforça a ideia comentando que os pais são modelos e ensinam, ainda que não intencionalmente, como agir socialmente. Os modelos de interação aprendidos desde a infância repercutem em todas as outras fases do desenvolvimento dos sujeitos influenciando na regulação das emoções e estilos de apego.

De acordo com Rincón e Pineda (2010), a construção do projeto migratório traz uma série de elementos que implicam a quebra de padrões e a implantação de novas estratégias de organização familiar. Haydar, Velez e López (2011), Martínez (2009), Rincón e Pineda (2010), e Villamizar e Moreno (2011), a meu ver, tratam a parentalidade transnacional como central em suas pesquisas com as famílias em contexto migratório. Abordam, principalmente, as estratégias que dão sustentação a esse estilo de vida. A respeito da manutenção da unidade familiar e da superação dos custos emocionais após os deslocamentos entre Estados nações. Parella (2007: 174) informa que: La reducida incidencia de la desintegración familiar evidencia el eficaz. funcionamiento de la familia a nivel transnacional, en el sentido de convertirse em una forma 'normal' y adecuada de desenvolverse para muchas familias.

Para Haydar, Vélez e López (2011), o papel dos pais e mães transmigrantes diz respeito à ajuda, estabelecimento de limites, aconselhamento, organização de estratégias de comunicação, além de exercer autoridade e planejar a utilização das remessas financeiras.

Villamizar e Moreno (2011: 100) corroboram com a perspectiva dos autores acima citados e complementam afirmando que: 
En el caso de las migraciones internacionales de padres y madres se presenta uma sensación de este tipo de pérdida oscilante, pues se continúa con cierta presencia em la distancia, se tejen sueños y expectativas sobre esta relación, los vínculos adquieren una especificidad, al tiempo que el padre o la madre están físicamente ausentes, mantienen la presencia psicológica y se buscan formas vinculantes a través de varias estrategias comunicativas.

De acordo com Rincón e Pineda (2010), a migração faz com que as relações parentais se desloquem para o espaço transnacional que se firma por meio da virtualidade, ao mesmo tempo em que ocorre um fluxo contínuo entre a localidade hospedeira e a de origem.

Haydar, Vélez e López (2011) discutem o exercício da autoridade a distância. Há muitos relatos evidenciando ser esse um aspecto da dificuldade nas relações parentais, principalmente quando os adolescentes estão envolvidos. De acordo com as autoras, esses personagens experimentam a ambiguidade de querer ter autonomia e liberdade e, ao mesmo tempo, demandam a presença do(s) genitor(es) e a possibilidade de compartilhar aspectos da vida cotidiana com eles.

Villamizar e Moreno (2011) investigaram os afetos e emoções parentais no contexto transnacional e mostram quatro diferentes relações afetivas que podem se estabelecer entre pais e mães migrantes e seus filhos: pode ocorrer a dissolução de laços parentais que até então eram de proximidade; também se verificam relações nas quais os laços eram conflituosos e com o processo migratório, transformam-se, acomodando vínculos de intimidade entre pais e filhos; indica-se ainda a possibilidade de manutenção dos laços afetivos vivenciados antes do deslocamento; e, por fim, identificam-se as situações em que a distância relacional existente na localidade de origem continuou após a migração. Nota-se com isso a heterogeneidade das relações e as inúmeras possibilidades de transações que se estabelecem no contexto migratório.

Haydar, Vélez e López (2011) relatam ainda a existência de relações parentais que se mantêm unicamente pautadas na função de provimento de bens materiais necessários à sobrevivência e ao contato com o cuidador do(s) filho(s) para tomar decisões relacionadas à saúde e educação quando necessário, estabelecendo vínculos superficiais e limitados. 
Um fato de extrema importância para a integridade emocional das crianças e adolescentes que possuem genitores migrantes, segundo Villamizar e Moreno (2011), é a organização do processo de deslocamento. Essas autoras mostram relatos que registram os sentimentos de abandono, principalmente quando a separação se dá de forma abrupta, sem dar espaço para os que permanecem reorganizar-se diante da separação. Enfatizam ainda o fato de os filhos, por vezes, serem muito novos e dependentes dos pais para entenderem os motivos envoltos no deslocamento. Sugerem, que, para que esse momento seja menos traumático, o projeto deve ser compartilhado por todos os membros da família.

Parella (2007) e Villamizar e Moreno (2011) enfatizam a existência de aspectos positivos e negativos nas relações entre os genitores e seus filhos, sem deixar, no entanto, de destacar os afetos ambivalentes que envolvem a percepção de abandono e o reconhecimento da abnegação dos pais.

Ademais dos autores citados, Rincón e Pineda (2010) indicam que os sentimentos negativos identificados com maior frequência relacionamse à apatia, hostilidade, tristeza e saudades que podem se manifestar entre crianças e adolescentes, por intermédio do decaimento do rendimento escolar e comportamento agressivo, principalmente no primeiro ano após o deslocamento. No entanto, Parella (2007) ressalta que essas situações, na maior parte das vezes, são temporárias e que a sua agudez ou o seu prolongamento requerem ajuda profissional.

Martínez (2009) observa que o envio de remessas monetárias tem como objetivo não apenas manter economicamente os que ficaram, mas também atenuar as mudanças que se estabeleceram com a separação. A esse respeito, Parella (2007) informa que as remessas monetárias representam proximidade, compromisso, cuidado e conservação do papel na família, diminuindo, assim, possíveis tensões entre o migrante e o seu grupo familiar, e atenuando a saudade e a percepção de abandono ao reafirmar os motivos da separação.

Rincón e Pineda (2010) informam que as remessas também significam mudança econômica e a possibilidade de construção de planos de ascensão social, principalmente para as crianças, adolescentes e jovens que têm a possibilidade de acessar melhor qualidade de vida que se reflete em áreas como saúde, educação e desenvolvimento de uma carreira. No entanto, Martínez (2009) mostra-se preocupada com o papel do dinheiro nas relações afetivas 
parentais e no desenvolvimento psicossocial de alguns adolescentes e jovens que permanecem na localidade de origem, sem construir um plano de vida independente das remessas que lhes são enviadas.

Rincón e Pineda (2010) informam ainda que os pais, mais do que as mães, têm a percepção de perda da autoridade parental. Os autores discutem a existência de diferentes papéis na determinação de maternidade e paternidade. Enquanto a paternidade é entendida principalmente a partir do exercício da autoridade, a maternidade é representada pelas relações afetivas, que não são tão perceptivelmente ocupadas pelos cuidadores.

Haydar, Vélez e López (2011), e Villamizar e Moreno (2011) afirmam que o rompimento dos laços parentais deve-se principalmente ao distanciamento (afetivo e econômico) do pai, mais do que da mãe transmigrante, ocorrendo com maior frequência quando há ruptura do subsistema conjugal. As autoras também indicam como elementos motivadores de distanciamento afetivo a quebra de promessas, deixar de enviar remessas, a diminuição de comunicação aberta e direta ou inexistência desse contato.

Por isso, Villamizar e Moreno (2011) reforçam a importância da manutenção constante de comunicação e de encontros mesmo que esporádicos com os filhos tanto na localidade de origem como na de destino para que se mantenha e atualize os vínculos parentais. Rincón e Pineda (2010: 92) também compartilham essa ideia e expõem que:

De igual manera, los encuentros esporádicos son especialmente necesarios para recrear el vínculo entre padres e hijos o el de pareja, bien sea que el migrante viaje a Colombia o que sus hijos y cónyuge viajen a España. De esta manera, todos pueden tener ese contacto físico que se anhela en la distancia y propicia un acercamiento de la realidad del otro, que les ayuda a entender el por qué de sus determinaciones y actuaciones; así como fortalecer los lazos sentimentales y construir nuevas experiencias y momentos juntos.

Parella (2007) também verifica que a promessa de reagrupação permeia o imaginário da maior parte das famílias, configurando-se numa das estratégias que permitem o abrandamento dos sentimentos dolorosos relacionados à separação. 


\title{
Conjugalidade transnacional
}

Ferés-Carneiro (2010) e Wagner (2011) entendem conjugalidade como um fenômeno psicossocial, em que os personagens relacionais constroem um projeto de vida em conjunto tendo como base a convivência afetiva e outros elementos como a sexualidade, a criação de filhos e uma trama compartilhada de valores, costumes e comportamentos.

Ferés-Carneiro (2010) expõe que gradativamente, em decorrência de transformações na sociedade contemporânea, os relacionamentos conjugais tradicionais, regidos por modelos sexistas, vêm cedendo lugar a uma nova forma de relação, na qual a mulher reivindica igualdade e há uma negociação constante levando ao estabelecimento de outras bases para a manutenção dos vínculos afetivos. Nesse sentido, Wagner (2011: 41) verifica que:

\begin{abstract}
A coexistência de valores e padrões tradicionais e atuais se desdobra em mudanças nas motivações subjacentes aos novos modos de relacionamento amoroso na contemporaneidade. As diferenças entre os posicionamentos de homens e mulheres conduzem a alguns impasses frequentemente estabelecidos nas relações conjugais contemporâneas. As negociações conjugais requerem o reconhecimento da autonomia e da independência dos parceiros, considerando a satisfação das necessidades individuais, sem deixar de levar em conta a complementaridade conjugal.
\end{abstract}

Em relação às análises da categoria conjugalidade transnacional os autores abordam muito mais a vivência parental e o papel dos cuidadores que propriamente a conjugalidade.

Haydar, Vélez e López (2011) relatam que as relações conjugais transnacionais, da mesma forma que as parentais, se estruturam mediante a construção de um cotidiano compartilhado, além da reedição dos planos e do aparecimento e cumprimento de promessas que se dão por meio do contato estabelecido a partir das tecnologias de comunicação.

Parella (2007) relata que com o distanciamento do parceiro, as mulheres passam a ter sentimentos ambivalentes que trafegam pela autonomia obtida e a pela solidão. Relata que essa autonomia perpassa a afirmação de seus direitos, 
a administração dos recursos econômicos e o aumento do seu status numa sociedade com características marcadamente patriarcais.

Pedone (2008) ressalta que os filhos têm uma participação significativa na permanência da união conjugal a distância ao contribuírem para negociações, ao mesmo tempo em que são fundamentais na manutenção de contato frequente. Segundo a autora, o reconhecimento do esforço do "outro" e o perdão por possíveis ingerências financeiras e infidelidades também contribuem para a manutenção da relação.

Parella (2007) observa que a crescente feminização do trabalho altera as configurações do processo migratório possibilitando a modificação da representação da mulher no contexto sociocultural das suas localidades de origem. Assim como Haydar, Vélez e López (2011), Pedone (2008) considera a existência de perspectivas diferentes na representação da migração masculina e feminina nas localidades de origem e destino, com a permanência de alguns valores patriarcais enraizados.

Pedone (2008) verifica que ainda ocorre uma divisão sexual dos papéis familiares de forma desigual, assim como uma maior responsabilização da mulher pelos novos arranjos estabelecidos, associando-a, mais frequentemente, ao abandono do lar e dos filhos.

Parella (2007) revela que os meios de comunicação transnacionais também são usados como reafirmação do poder masculino. Informa que em algumas situações há um controle minucioso do lar e da parceira pelas chamadas telefônicas e contato em tempo real via computador. Expõe ainda que quando a mulher é a primeira a emigrar lhe é imputado o dever moral de auxiliar no deslocamento do seu parceiro, que migra e deixa as responsabilidades de cuidado com outras pessoas da família, evitando a perda do seu papel como provedor.

No que se refere à manutenção da relação a distância, Parella (2007) informa que essa relação pode ir se desgastando e gerando conflitos decorrentes da distância e do tempo prolongado de separação, é comum a solidão, o abatimento, o temor da infidelidade e da deterioração do vínculo afetivo.

Haydar, Vélez e López (2011) verificam como elementos presentes nas relações desgastadas a pouca expressão afetiva nos contatos virtuais, a diminuição do contato por meio das tecnologias da comunicação, descumprimento de planos e promessas que faziam parte do projeto migratório. 
Outros pontos identificados por Parella (2007) são o surgimento do ciúme e da desconfiança, além da circulação de rumores que criam tensão e influem no rompimento das relações.

Assim com a autora acima, Haydar, Vélez e López (2011) e Pedone (2008) constatam que nas relações transnacionais há uma maior probabilidade de rompimento conjugal do que dos vínculos parentais, e que o término da relação conjugal é atribuído principalmente às infidelidades e as suspensões dos envios de remessas de dinheiro. Outro ponto abordado por Haydar, Vélez e López (2011) é que, em muitos relacionamentos, o vínculo conjugal já se encontrava comprometido por fatores como a violência doméstica, e a migração funcionou como um catalisador, isto é, um meio de reorganização dos vínculos familiares e de fortalecimento da decisão pela separação.

\section{Cuidadores}

Quanto à categoria cuidadores verificou-se que esse é um tema bastante discutido e apontado como um dos principais ingredientes que propiciam a execução do projeto migratório. Martínez (2009) e Soares (2002) ressaltam a importância das redes sociais que contribuem para viabilizar e consolidar o deslocamento. Essas redes dizem respeito, principalmente, a familiares, vizinhos e amigos que são fundamentais no papel de cuidadores dos filhos dos migrantes.

Por conta das novas condições familiares, muitos papéis tradicionalmente designados ao pai ou a mãe já não são exercido com tanta exclusividade. As redes familiares acabam cumprindo funções de cuidado, portanto, de suporte às ausências dos progenitores, assegurando a manutenção e socialização de seus membros (HAYDAR, VÉLEZ e LÓPEZ, 2011).

De acordo com todos os artigos analisados, a categoria cuidadores referese àquelas pessoas, geralmente mulheres, pertencentes à rede familiar, que assumem a responsabilidade de tutoria dos filhos do(s) transmigrante(s), e dão suporte aos que migraram, participando da organização e transmissão das antigas e novas rotinas familiares. Haydar, Vélez e López (2011: 2.048) complementam essa definição com o seguinte comentário: 
La migración del padre y/o la madre implica cambios para el progenitor y lãs personas de la red parental que se quedan con los hijos e bijas, asumir el cuidado directo de estos, y con ello, ser participes activos en los procesos de socialización a través del intercambio de aprendizajes, normas, pautas de crianza, hábitos, creencias y en si todos los referentes sociales y culturales que les permitan su construcción como seres humanos.

Martínez (2009) e Rincón e Pineda (2010) também realçam que, além das responsabilidades com a integridade física da criança e do adolescente, também faz parte do papel atribuído ao cuidador o suporte emocional, principalmente em etapas críticas como o primeiro ano de migração e durante a adolescência. Parella (2007) ressalta ainda que o cuidado fornecido pelos familiares impede que a sociedade considere que as crianças e os adolescentes estejam em situação de abandono.

Para Villamizar e Moreno (2011); Haydar, Vélez e López (2011); Parella (2007), a familia extensa, principalmente as figuras parentais femininas, se organizam para fornecer afeto e cuidados às crianças e adolescentes que permanecem na localidade de origem.

Verifica-se que para Haydar, Vélez e López (2011); Martínez (2009); Rincón e Pineda (2010) e Pedone (2008), os principais cuidadores são as mães, as avós, as tias, o pai, os filhos mais velhos ao atingirem a maioridade e, com menor expressividade, o cuidador remunerado.

Rincón e Pineda (2010) informam que, geralmente, quando esse personagem não é um dos genitores, fica responsável apenas por decisões de baixo impacto, tornando-se um transmissor da decisão dos pais e mães em questões de grande responsabilidade, envolvendo geralmente educação, saúde, punições, entre outros. Haydar, Vélez e López (2011) assim como Parella (2007) verificaram que o cuidado dos adolescentes é descrito como permeado por conflitos, o que pode provocar a troca de cuidadores.

Com relação ao papel desempenhado pelas avós, Pedone, 2008, relata que ser guardiã dos netos é um papel que vem se perpetuando desde que as mulheres passaram a transitar nos espaços públicos, incorporando-se ao mercado de trabalho e a processos como os deslocamentos nacionais e internacionais.

Segundo Parella (2007), as avós enfrentam algumas problemáticas ao 
exercer o papel de tutoria; os conflitos relacionam-se principalmente à criação dos adolescentes, fato que demanda bastante energia e atividade para lidar com os conflitos intergeracionais que frequentemente surgem. A autora também expõe que a possibilidade de migração da avó cuidadora é frequentemente mencionada, no entanto, constata-se que estas mulheres possuem inúmeras amarras na localidade de origem o que torna menos frequente a sua participação no projeto migratório.

Pedone (2008) relata que, em geral, quando a tia é a cuidadora, estabelecem-se dinâmicas diferenciadas nas relações com os genitores, em especial com a mãe. Isso ocorre principalmente, segundo a autora, pelas similaridades com a organização familiar original, que faz com que as crianças e adolescentes estabeleçam laços tão próximos, que criam tensão com as mães transmigrantes e repercutem na aceitação ou recusa de um plano de reunião com seus pais na comunidade hospedeira.

Martínez (2009) e Pedone (2008) também identificam que muitas vezes os filhos adolescentes e jovens assumem novos papéis no interior das famílias, sendo responsáveis por questões que antes eram atribuídas aos pais e mães, desenvolvendo atividades que lhes sobrecarregam e para as quais não possuem repertório emocional.

Outra problemática identificada por Villamizar e Moreno (2011) referese à discrepância que ocorre entre a autoridade do(s) genitor(es) e do cuidador. Alguns pais tendem a ser mais permissivos com os filhos e acabam quebrando com a autoridade do cuidador formando tensão nas relações cuidador-filhos e cuidador-migrantes.

A respeito das mudanças nas relações parentais no mundo contemporâneo, Feres-Carneiro (2010) informa que, ao romper com o padrão tradicional, há uma desorientação dos pais, que ao se deparar com situações-problema oscilam entre o autoritarismo e a permissividade. De acordo com a autora, esses estilos de criação podem suscitar duas percepções opostas nas crianças ou adolescentes: o sentimento de hostilidade e a negação da autoridade ou o sentimento de abandono e insegurança. 


\section{Considerações finais}

Por fim, verifica-se que os autores consideram que a migração, por um lado, acentua algumas experiências familiares e pode aprofundar problemáticas já vivenciadas, por outro, auxilia na manutenção e reforça os laços afetivos. Nesse sentido, os temas discutidos não devem ser considerados de forma estanque e inflexível, pois esse é um campo de estudo dinâmico, interdisciplinar e que se caracteriza pela possibilidade de construção e desconstrução das suas categorias.

A parentalidade transnacional aparece como tema central na maior parte das pesquisas analisadas, compreende-se que há heterogeneidade nas relações parentais e inúmeras possibilidades de transações.

Inferiu-se que a conjugalidade transnacional é analisada principalmente sob o foco das relações de gênero, que expõem tanto a conquista de autonomia pelas mulheres quanto a manifestação de estruturas patriarcais enraizadas. Constata-se ainda que, com o deslocamento entre espaços transnacionais, há uma probabilidade maior de ruptura dos laços conjugais do que dos laços parentais. Ao mesmo tempo, aumenta a importância da família extensa, principalmente das avós e tias, pois se organizam na localidade de origem para fornecer afeto e cuidados às crianças e adolescentes filhos dos transmigrantes.

Também se averiguou no discurso dos autores a similaridade no que diz respeito às estratégias organizadas em torno do projeto migratório. A maior parte das investigações revela que a família transnacional estabelece uma relação dinâmica, que subjaz a construção de um cotidiano compartilhado, por meio da comunicação constante; da reunião na localidade hospedeira ou de origem, mesmo que por curtos períodos; do estabelecimento e cumprimento de promessas, além da participação no provimento pelas remessas financeiras.

\section{Referências}

FERÉS-CARNEIRO, Terezinha. Casal e família: permanências e rupturas. São Paulo: Casa do Psicólogo, 2010, p. 315.

FONSECA, Yone F.; FEITOZA, Elaine C. D.; LIMA, Márcia F. Fortalecimento do vínculo entre pais e filhos. In: NEIVA, Kathia Maria Costa 
e (Cols.). Intervenção Psicossocial - aspectos teóricos metodológicos e experiências práticas. São Paulo: Vetor, 2010, p. 148-174.

HAYDAR, María del Pilar Morad; VÉLEZ, Gloria Bonilla; LÓPEZ, Mercedes Rodríguez. Familias desde el vivir transnacional: cambios y permanencias en la cotidianidad de las formas familiares en Colombia. In: CASTAÑO, F. J. García; KRESSOVA, N. (Coords.). Actas del I Congreso Internacional sobre Migraciones en Andalucia. Granada: Instituto de Migraciones, 2011, p. 2.0412.052. Anais... Disponível em: <www.scielo.br/scielo.php?pid=S01028392005000300007\&script=sci_arttext $>$. Acesso em: 31 março de 2012.

MARTÍNEZ, Adriana Zapata. Familia transnacional y remesas: padres y madres migrantes. Revista Latinoamericana de Ciencias Sociales, Niñezy Juventud, vol. 7, núm. 2, jul.-dez., 2009, p. 1.749-1.769. Disponível em: <http://www. scielo.br/scielo.php?pid=S0102-8392005000300007\&script $=$ sci_arttext $>$. Acesso em: 10 de junho de 2012.

PARELLA, Sónia. Los vínculos afectivos y de cuidado en las familias transnacionales migrantes ecuatorianos y peruanos en España. Revista Migraciones Internacionales, vol. 4, n. 02, jul.-dez., 2007, p. 151-188. Disponível em: < redalyc.uaemex.mx/pdf/151/15140206.pdf >. Acesso em: 2 de junho de 2012.

PEDONE, Claudia. "Varones aventureros" vs. "Madres que abandonan": reconstrucción de las relaciones familiares a partir de la migración ecuatoriana. Rembu - Revista Interdisciplinar da Mobilidade Humana. Ano XVI, n. ${ }^{\circ}$ 30, 2008, p. 45-64. Disponível em: <http://www.scielo.br/scielo.php?pid=S0102$8392005000300007 \&$ script=sci_arttext $>$. Acesso em: 15 de junho de 2012.

RIBEIRO, Gustavo Lins. Cap. 5 A condição da transnacionalidade. In: Cultura e politica no mundo contemporâneo: paisagens e passagens. Brasília: Editora Universidade de Brasília, 2000, p. 93-124.

RINCÓN, Luz Adriana González; PINEDA, Jair Eduardo Restrepo. Prácticas de continuidad de los vínculos parentales en las familias transnacionales colombianas en España (Comunidad Valenciana, España - Eje Cafetero, Colombia). Revista Latinoamericana de Estudios da familia, vol. 2, jan.-dez. 2010, p. 79-97. Disponível em: <http://www.scielo.br/scielo.php?pid=S0102$8392005000300007 \&$ script=sci_arttext $>$. Acesso em: 15 de junho de 2012. 
SASAKI, Elisa Massae, ASSIS, Gláucia de Oliveira. Teorias das Migrações Internacionais. GT - Migração: Sessão 3 - A migração internacional no final do século. In: XII Encontro Nacional da Associação Brasileira de Estudos Populacionais/ Abep, outubro de 2000, Caxambu. Anais... Disponível em: <http://abep.org. br/usuario/GerenciaNavegacao.php?caderno_id=184\&nivel=2>. Acesso em: 11 de abril de 2012.

SOARES, Weber. Da metáfora à substância: redes sociais, redes migratórias e migração nacional e internacional em Valadares e Ipatinga. 2002, 344 folhas. Tese (Doutorado em Demografia do Centro de Desenvolvimento e Planejamento Regional). Faculdade de Ciências Econômicas, Universidade Federal de Minas Gerais - UFMG. Belo Horizonte, 2002. Disponível em: $<$ http://www.bibliotecadigital.ufmg.br/dspace/bitstream/1843/FACE5NGJ5E/1/weber_soares.pdf>. Acesso em: 18 de junho de 2012.

VALDERRAMA, Cristina Blanco F. de. Transnacionalismo. Emergencia y fundamentos de una nueva perspectiva migratoria. Papers: revista de sociologia, n. 85, 2007, p. 13-29. Disponível em: < www.raco.cat/index.php/papers/ article/.../94201>. Acesso em: 12 de maio de 2012.

VILLAMIZAR, Yolanda Puyana; MORENO, Alejandra Rojas. Afectos y emociones entre padres, madres e hijos en el vivir transnacional. Revista Trabajo Social. Bogotá, n. 13 , jan.-dez., 2011, p. 95-110. Disponível em: www.revistas. unal.edu.co/index.php/.../28726. Acesso em: 12 de maio de 2012.

WAGNER, Adriana. Desafios Psicossociais da família contemporânea: pesquisas e reflexões. Porto Alegre: Artmed, 2011, p. 19-35. 